\title{
Epidemiological Study of Non-communicable Diseases Among Patients Attending Nutritional Clinic in Baquba Teaching Hospital
}

\author{
Moneam Akram Hassan (FIBMS) ${ }^{1}$, Abd Alsalam Harfash Hassan (FIBMS) ${ }^{2}$ and \\ Nadhim Ghazal Noaman $(\mathrm{PhD}, \mathrm{MFPH})^{3}$
}

Abstract

Background: Non-communicable diseases are chronic diseases with long duration resulting from a combination of many factors like genetic, physiological, environmental, and lifestyle. Factors like poor diet, lack of exercise, tobacco, drugs, alcohol, family, and environment are risk factors for non-communicable diseases.Non-communicable diseases have huge economic consequences due to health care costs and lost economic productivity. Noncommunicable diseases are responsible for $63 \%$ of the total death. Modifiable risk factors due to lifestyle can be controlled or reduced by intervention like lack of exercise, smoking, alcohol, unbalanced diet while non-modifiable risk factors cannot be reduced or controlled like age, gender, genetics. Improper maternal nutrition in utero and during the first year of life is associated with the risk of non-communicable diseases in adulthood. Obesity is now a public health problem because of strong association with hypertension, coronary heart disease, type 2 diabetes and stroke.

Objective: To determine non -communicable diseases among patients attending a nutrition clinic in Baquba Teaching Hospital and to assess the diseases in relation to age, gender, residency, occupation, and educational level.

Patients and Methods: This descriptive study was conducted in Baquba Teaching Hospital, a review of patients' records was done from the start of January 2015 to $31^{\text {st }}$ December 2017. Data were collected by specially designed questionnaire which includes age, gender, height, weight, occupation, residency, and educational level. Results presented in tables with numbers and percentages.

Results: The total number of records were (891) .obesity and morbid obesity (64.2\%). Obesity $(52.7 \%)$ followed by hypertension $(20.3 \%)$. Most of the cases were female $(66.7 \%)$. The age group of (31-40) year was mostly affected (23.2\%). Urban residents (77.2\%) of cases .House wives $(48.2 \%)$ followed by students $(23.1 \%)$. (63.8\%) of cases were graduated from primary and secondary school.

Conclusion: Most the cases were obese. Female affected more than male, majority of cases in the age group below 50 years, urban residents more than rural residents, most of cases were house wives, matority of cases were graduated from primary and secondary school.

Keywords: Non-commnicable diseases, obesity, lifestyle Corresponding Author: drnadhimg@yahoo.com 
Received: $22^{\text {th }}$ January 2020

Accepted: $12^{\text {th }}$ March 2020

DOI:https://doi.org/10.26505/DJM.19025220122

\section{${ }^{1,2}$ Baquba Teaching Hospital-Dyiala - Iraq \\ ${ }^{3}$ College of Medicine -Diyala University- Diyala- Iraq}

\section{Introduction}

Non-communicable diseases are chronic diseases with a long duration resulting from a combination of genetic, physiological, environmental, and behavioral factors. Noncommunicable diseases include cardiovascular diseases, cancers, chronic respiratory diseases, and diabetes[1]. Noncommunicable diseases are responsible for $63 \%$ of total deaths worldwide[2]. The mortality rate due to non-communicable diseases increased by up to a $65 \%$ in 2010 [3].

Non-communicable diseases are predisposed by risk factors which are poor diet, lack of exercise, tobacco, drug, alcohol, family history, and environment[4]. World Health Organization (WHO) has prioritized four modifiable risk factors like physical inactivity, tobacco use, alcohol use, and unhealthy diets while non-modifiable risk factor that can't be controlled or reduced like (Age, Gender, Race and family history genetics)[5].

Non-communicable diseases have a huge economic burden due to health care costs and loss of productivity[6].

Non-communicable diseases are responsible for catastrophic health expenditure among the uninsured[7].

Inadequate maternal nutrition and during the first years of life were regarded as risk factors for non-communicable diseases in adulthood[8].Overweight and obesity regarded a worldwide health problem because it is associated with increased risk of chronic diseases like hypertension, ischemic heart diseases, type 2 diabetes, stroke, gall bladder diseases, certain types of cancer, and other disorders[9]. Obesity was described as a chronic disease by WHO that is so prevalent in both developed and developing countries [10].

Physical activity, better diet, and access to vaccines play important role in prevention and reduction of the prevalence of noncommunicable diseases that in turn improves the quality of life and decrease health care costs [11]. The aims of this study are to determine non-communicable diseases among patients attending to nutrition clinic in Baquba teaching hospital. To assess these patients in relation to (Age, Gender, Residency, Occupation, Educational level).

\section{Patients and Methods}

A descriptive study was conducted from the start of January 2015 to $31^{\text {st }}$ of December 2017 , the rercords of patients attending to nutrition clinic in Baquba Teaching Hospital were included.

This hospital is the central hospital in Diyala province. Data were collected by specially designed questionnaire include the following data (Name, Age, Gender, Height, Weight, Occupation, Residency, Education level). 


\section{Statistical analysis}

The collected data were analyzed manually and presented by tables with numbers and percentages.

\section{Results}

Total number of cases during the study period were (891). Obesity and morbid obesity form more than $63 \%$ of cases who attended to nutrition clinic as shown in Table (1).

Distribution of cases according to chronic diseases show that obesity form $(52.7 \%)$ followed by hypertension $(20.3 \%)$ from all those with non-communicable diseases (311) as shown in Table (2).
Most of the cases were females $(66.7 \%)$ while males (33.3\%), as shown in Table (3). Most of the cases were in age groups (31-40) yr $23.2 \%$ followed by age groups $(21-30) y r$ $21.1 \%$ and (41-50)yr $19.8 \%$ as shown in Table (4). Urban residents form (77.2\%) of cases as shown in Table (5). According to the occupation, the majority of cases were housewives $(48.2 \%)$ followed by students $(23.1 \%)$ and governmental employees $(20.7 \%)$ as shown in Table (6). More than $(63.8 \%)$ of cases were graduated from primary and secondary schools and a minority of cases were illiterate as shown in Table (7).

Table (1): Distribution of cases according to Body Weight

\begin{tabular}{||l||c|c|}
\hline \multicolumn{1}{|c|}{ Body Weight } & No & $\%$ \\
\hline \hline Obesity & 381 & 42.8 \\
\hline \hline Morbid obesity & 191 & 21.4 \\
\hline \hline Increase in weight & 181 & 20.3 \\
\hline \hline Thin & 102 & 11.5 \\
\hline \hline Normal weight & 36 & 4 \\
\hline \hline Total & 891 & 100 \\
\hline
\end{tabular}

Table (2): Distribution of cases according to Non-Communicable Diseases

\begin{tabular}{|l||c||c||}
\hline \multicolumn{1}{|c||}{ Diseases } & No & $\%$ \\
\hline \hline Obesity & 164 & 52.7 \\
\hline \hline Hypertension & 63 & 20.3 \\
\hline \hline Diabetes & 13 & 4.2 \\
\hline \hline Heart diseases & 5 & 1.61 \\
\hline \hline Thyroid gland & 4 & 1.3 \\
\hline \hline Asthma & 2 & 0.6 \\
\hline \hline Renal disease & 1 & 0.32 \\
\hline \hline More than one disease & 59 & 18.97 \\
\hline \hline Total & 311 & 100 \\
\hline *Those with non-communicable disease were excluded
\end{tabular}

Table (3): Distribution of cases according to Gender

\begin{tabular}{|l||c||c||}
\hline \multicolumn{1}{|c|}{ Gender } & No & $\%$ \\
\hline \hline Female & 594 & 66.7 \\
\hline \hline Male & 297 & 33.3 \\
\hline \hline Total & 891 & 100 \\
\hline
\end{tabular}


Table (4): Distribution of cases according to Age Group

\begin{tabular}{|c||c||c|}
\hline Age group & No & $\%$ \\
\hline $1-10$ & 85 & 9.5 \\
\hline \hline $11-20$ & 147 & 16.5 \\
\hline \hline $21-30$ & 188 & 21.1 \\
\hline \hline $31-40$ & 207 & 23.2 \\
\hline \hline $41-50$ & 176 & 19.8 \\
\hline $51-60$ & 70 & 7.9 \\
\hline \hline $61-70$ & 16 & 1.8 \\
\hline \hline$>70$ & 2 & 0.2 \\
\hline \hline Total & 891 & 100 \\
\hline
\end{tabular}

Table (5): Distribution of cases according to Residency

\begin{tabular}{|l|l|c|}
\hline \multicolumn{1}{|c|}{ Residency } & No & $\%$ \\
\hline \hline Urban & 688 & 77.2 \\
\hline Rural & 203 & 22.8 \\
\hline \hline Total & 891 & 100 \\
\hline
\end{tabular}

Table (6): Distribution of cases according to Occppation

\begin{tabular}{|l||c|c||}
\hline \multicolumn{1}{|c|}{ Occupation } & No & $\%$ \\
\hline \hline House wife & 391 & 48.2 \\
\hline \hline Student & 187 & 23.1 \\
\hline \hline Government employees & 168 & 20.7 \\
\hline \hline Wage earner & 35 & 4.3 \\
\hline \hline Military & 11 & 1.4 \\
\hline \hline Medical staff & 10 & 1.2 \\
\hline \hline Retired & 9 & 1.1 \\
\hline \hline Total & 811 & 100 \\
$*$ Children were excluded
\end{tabular}

Table (7): Distribution of cases according to Educational Level

\section{Discussion}

In this study obesity and morbid obesity form more than $64 \%$ and this could be explained that the high prevalence of obesity in both adult men and women $32.2 \%, 35.5 \%$ respectively. The prevalence of obesity was increasing continuously in the last ten years

\begin{tabular}{|c||c||}
\hline No & $\%$ \\
\hline 86 & 9.7 \\
\hline 319 & 35.8 \\
\hline 250 & 28 \\
\hline 236 & 26.5 \\
\hline 891 & 100 \\
\hline
\end{tabular}

for women and maybe for men [12]. Patients with obesity, hypertension, and diabetes mellitus form (77.2) of cases and this could be attributed to fact that obesity is a risk factor with a strong association for more than 20 chronic diseases[13]. There is a marked 
increase in cardiovascular diseases and another non-communicable disease due to epidemiologic transition and these diseases had a great burden on developing countries and regarded as a leading cause of mortality and disability.

According to gender in this study female was more than male (66.7\%) and this agrees with study in China which showed that Noncommunicable diseases were lower in men than women[14], and this could be explained that body mass index was increased significantly among females in the last four decades[15].

Majority of cases were in young adult and up to 50 years and this agree with WHOSAGE data study[16]. And the explanation for that is related to lifestyles like physical activity, a dietary habit that leads to obesity and chronic diseases. The majority of cases were reported among urban residents and this could be due to rapid urbanization which is associated with an increase in incidence and prevalence of non-communicable diseases.

[17]. Rural and urban living can determine health through arrange of environmental, social and cultural factors[18]. This result agree with study by Allenders, et al (2010)[19].

The majority of cases were housewives and this could be explained that women are more affected than men in this study and most of women were housewives and this agrees with the study by Jain et al (2007)[20].

More than $63 \%$ of cases were students of primary and secondary school and those students were referred to nutrition clinic according to obesity survey program which is implemented according to school health services program and this agree with study by Manlike and Knobler (2006) [21].

\section{Conclusions}

1-Total number of cases during the study period was (891).

2-Obesty forms $(52.7 \%)$ of cases

3 -Females are more than males $(66.7 \%)$.

4-Most of the cases in the age group (31-40) years $(23.2 \%)$.

5-Urban residencies form $77.2 \%$ of the cases. 6-The majority of the cases were housewives $(48.2 \%)$.

$7-(63.8 \%)$ of cases have primary and secondary school graduation

\section{Recommendations}

1-Health education about obesity and its relation with other non-communicable diseases.

2-There must be program in schools and universities to prevent obesity

3-There must be good attention to sport in schools, universities, and public

4-Health services should be directed to noncommunicable diseases regarding diagnosis, treatment to prevent complications

\section{References}

[1]Risk factors collaborators. Global , regional, and national comparative risk assessment of 79 behavioral, environmental and occupational, and metabolic risks or clusters of risks , $1990-2015$ : a systematic analysis for the Global Burden of Disease study 2015 . Lancet , 2016 ;388 (10053) : 1659 - 1724 .

[2]Cause - specific mortality , 2008 : WHO region by country . Geneva : World Health Organization , 2011 (http:llapps.WHO.int/gho/data/node.main.88 7? lang=en). 
[3]Lozano R , Naghavi M , Foreman K , etal . Global and regional mortality from 235 causes of death for 20 age groups in 1990 and 2010 : a systematic analysis for the Global Burden of Disease study 2010 . Lancet 2012 ; $380: 2095-2128$.

[4]Ezzati M,Riboli E. Behavioral and dietary risk factors for noncommunicable diseases . N Engl J Med , 2013; 369 : 954 - 64.

[5] Center of Disease Control and prevention (CDC) report 2013.

[6]Bloom DE , Cafiero ET , Jane - Llopis E , etal . The global economic burden of noncommunicable diseases. Geneva : world Economic Forum , 2011 (http://www.weforum.org/reports/globaIeconomic-burden-non-communicablediseases).

[7]Heeley E , Anderson CS, Hung Y, etal . Role of health insurance in averting economic hard ship in families after acute stroke in china . stroke $2009 ; 40: 2149$ 2156.

[8]Barker DJP . Sir Richard Doll Lecture : developmental origins of chronic disease . Public Health 2012; 126:185-189.

[9]National Institutes Health. Clinical guidelines on the identification, evaluation , and treatment of over weight and obesity in adults - obsity report . 1998; 6 : 51S - 209S . [10]World Health Organization . Report of a WHO Consultation on obesity . obesity : preventing and managing the global epidemic . Geneva : world Health organization , 1998. [11]World Health Organization ; preventing chronic diseases a vital investment ; World Health Organization cataloging in publication Data , 2005 , pg . 18.
[12]Flegal K.M. , Carrol M. D. , Ogden C.L. etal. ( January 13，2010 ).Prevalence and trends in obesity among US adults , 1999 2008 . JAMA. 303 (3) : 235.241. Available at http://jama.ama.org/cgi/content/full/303/3/23 5?ijkey=ijk Hq6yjn30. gkeytype=ref g siteid=amajnls.

[13]Prevelanc of over weight and obesity among adults diabetes - united stats . 19881994 and 1999-2002 morbidity and mortality weekly report 53:1066-1068.

[14]Yan Liu , Guofeng Liu Hongjian and Wu sex differences in non-communicable disease prevalence in china : a cross - sectional analysis of the china Health and Retirement Longitudinal study in 2011 . BMJ, December 2017:7 (12).

[15]Wang , Y. G,M . A. Beydoun.The obesity epidemic in the United States .Gender , age , socioeconomic ,racial / ethnic , and geographic characteristics :A Systematic review and Meta_Regression Analysis .Epidemiologic Reviews (2007). 1 :6-28.

[16]White, M.A, et al . gender , race and obsity- related quality of life at extreme level of obstiy . obstiy (2004) 12: 949-955.

[17]Erem C, Arsian C,Hacihusanoglu A,Deger O, Topbas M, ukinc $\mathrm{K}$, et al prevelance of obesity and associated risk factors in turkish population obes. Res. 2004 ;12(7):1117-27.

[18]Harpham T. (2009) . Urban health in developing Countries : what do we Know and where do we go ? Health and place ,15 (1), 107-116 do :15.1516/j. health place. 2008.03.004 [pub med] [Ref list].

[19]Allen der S , Lacey B, Webster P, Rayner M, Deepa M, Scarborough P, et al.Level of Urbanization and Non-Communicable 
Disease risk-factors in Tamil Nadu, India . Bulletin of the world Health Organization . 2010. April ; 88(4) : 297-304 do; 15.2471/BLT. Oq.o65847[PMC free article] [pub med].

[20]Jain, A. , etal. [November 2 , 2007] Revisioning success : How stigma perceptions of treatment, and definitions of success impact obesity and weight management in America strategies to overcome and prevent (STOP) obesity Alliance . Available ; http:www.stopobesityalliance.org/w.pcontent .assets/2003/06/report re-visioning success. [21]Malnick SD , Knobler H. (2009) The medical complications of obesity . OJM . 99(9) : 565-579. 